\title{
Preferência alimentar de Helicoverpa armigera a diferentes cultivares de soja com tecnologia Bt
}

\author{
Helicoverpa armigera food preference to different soybean cultivars with Bt technology
}

\author{
A. C. de Oliveira ${ }^{1}$; L. S. de Faria ${ }^{1}$; F. J. Carvalho ${ }^{2}$;. V. Oliveira ${ }^{1}$; V. Andaló ${ }^{* *}$ \\ ${ }^{1}$ Instituto de Ciências Agrárias, Universidade Federal de Uberlândia, 38500-000, Monte Carmelo-MG, Brasil \\ ${ }^{2}$ Instituto Federal Triângulo Mineiro, 38064-300, Uberaba-MG, Brasil
}

*vanessaandalo@ufu.br

(Recebido em 20 de junho de 2020; aceito em 16 de outubro de 2020)

\begin{abstract}
O uso de plantas transgênicas com tecnologia Bt para controle de Helicoverpa armigera (Hübner, 1805) (Lepidoptera: Noctuidae) tem sido uma ferramenta adotada dentro do plano de manejo da praga, no entanto, é necessário verificar a presença de populações resistentes do inseto. Teve-se por objetivo avaliar a atratividade, o consumo e a preferência alimentar de lagartas de H. armigera em cultivares de soja Bt. Para a avalição de atratividade e consumo foram liberadas lagartas de H. armigera em placas de Petri contendo quatro discos foliares, sendo dois discos de cultivar Bt e dois discos não-Bt. Na avaliação da preferência alimentar, uma lagarta foi disposta na área central da placa juntamente com dois discos de cada cultivar colocados equidistantes, resultando em doze discos foliares por placa. Em ambos os testes foram observadas lagartas em todas cultivares de soja. No teste de atratividade verificou-se que as cultivares Desafio IPRO e LG 60162 foram consideradas atrativas para H. armigera, enquanto a M 7739 IPRO foi considerada pouco atrativa para alimentação de lagartas de $H$. armigera. Na avaliação de consumo foliar, as cultivares Desafio IPRO e LG 60162 IPRO foram consideradas atrativas para o consumo. Em relação ao teste de preferência alimentar, a cultivar M 7739 IPRO foi a que teve menor preferência para alimentação de $H$. armigera. Trabalhos futuros devem ser desenvolvidos a fim de verificar em condições de campo se há preferência alimentar de $H$. armigera por diferentes cultivares de soja $\mathrm{Bt}$, já que fatores ambientais podem interferir no comportamento do inseto.
\end{abstract}

Palavras-chave: alomônio, Glycine max, preferência alimentar

The use of transgenic plants with Bt technology to control Helicoverpa armigera (Hübner, 1805) (Lepidoptera: Noctuidae) has been a method adopted within the pest management plan, however, it is necessary to verify the presence of resistant populations of the insect. Thus, the objective of the study was to evaluate the attractiveness, consumption and food preference of $H$. armigera caterpillars in Bt soybean cultivars. For attractiveness and consumption evaluation, H. armigera caterpillars were released in Petri dishes containing four leaf discs, two discs of Bt cultivar and two discs of non-Bt cultivar. In the evaluation of food preference, a caterpillar was placed in the central area of the Petri dish and two discs of each cultivar were placed equidistantly, resulting in twelve leaf discs per plate. In both tests, caterpillars were observed in all soybean cultivars. In the attractiveness test it was verified that the cultivars Desafio IPRO and LG 60162 were considered attractive for $H$. armigera, while the M 7739 IPRO was considered unattractive for $H$. armigera caterpillars feeding. In the evaluation of leaf consumption, the cultivars Desafio IPRO and LG 60162 IPRO were considered attractive for consumption. Regarding the food preference test, it was found that the cultivar M 7739 IPRO was the one that had the least preference for feeding H. armigera caterpillars. Future works should be developed in order to verify under field conditions whether there is a feeding preference of $H$. armigera by different Bt soybean cultivars, since environmental factors could interfere with the insect's behavior.

Keywords: allomone, Glycine max, food preference

\section{INTRODUÇÃO}

O Brasil é um dos maiores produtores mundiais de soja, na safra 2019/2020 a produção estimada é de 120,3 milhões de toneladas em uma área de $36.843,5$ mil ha, o que representa 2,7\% de aumento na área plantada em relação à safra passada [1]. Segundo dados da Secretaria de Comércio Exterior (SECEX) o Brasil exportou 69,74 milhões de toneladas de soja na safra 2019/2020, o que representa 
um crescimento de $36,3 \%$ em relação ao ano anterior, ficando em primeiro lugar no ranking de exportações brasileiras [2].

Dentre os principais problemas fitossanitários para o desenvolvimento adequado da cultura pode-se destacar a ocorrência de Helicoverpa armigera (Hübner, 1805) (Lepidoptera: Noctuidae), que era uma praga quarentenária no Brasil até 2013 quando foi registrada sua ocorrência no país. É um inseto considerado de difícil controle, em função de suas características biológicas e comportamentais. Possui ciclo de vida curto, elevada capacidade de dispersão, adaptação a diferentes condições climáticas, se alimenta de diversas plantas, dentre elas culturas agrícolas, como o algodoeiro (Gossypium hirsutum L. var. latifolium (Hutch)), o milho (Zea mays L.), o trigo (Triticum aestivum L.) e o feijoeiro (Phaseolus vulgaris L.), e também de diferentes partes das plantas, como cotilédones, brotos, folhas, grãos e vagens $[3,4,5]$.

Na cultura da soja, lagartas de H. armigera, causam danos em folhas, vagens e grãos, sendo que lagartas de primeiro instar possuem preferência alimentar por folhas novas, enquanto as lagartas de quarto e sexto instar não possuem preferência por um órgão específico, podendo se alimentar de folhas novas, velhas, vagens e grãos, sendo que o consumo do órgão vegetativo e/ou reprodutivo pode influenciar no desempenho da espécie $[6,7,8]$. Foi registrado prejuízo de US\$ 4 bilhões na safra brasileira de 2012/2013 pela ocorrência de H. armigera, sendo relatada sua ocorrência em cultivares transgênicas de soja contendo o gene $\mathrm{Bt}[4,9]$.

De acordo com o Ministério da Agricultura, Pecuária e Abastecimento (MAPA), existem 44 inseticidas químicos e biológicos, registrados para o controle de $H$. armigera na cultura da soja no Brasil, inclusive moléculas como benzoato de emamectina e metaflumizona liberadas inicialmente em caráter emergencial [10]. De acordo com Kuss et al. (2016) [11] inseticidas como flubendiamida, clorantraniliprole, espinosade, clorfenapir, indoxacarbe e metoxifenozida, apresentam desempenho considerado satisfatório causando mortalidade em $H$. armigera. No entanto, Pereira et al. (2020) [12] verificaram uma redução na suscetibilidade de populações de $H$. armigera no Brasil a inseticidas do grupo das diamidas, indicando o rápido desenvolvimento de resistência.

Pomari-Fernandes et al. (2015) [14] destaca que várias etapas devem ser consideradas para o manejo correto da praga, podendo-se destacar a identificação correta da espécie e o emprego do manejo integrado, considerando-se o uso dos produtos com maior eficácia, o momento correto da aplicação e a tecnologia de aplicação apropriada para atingir o alvo.

Outro método que pode ser empregado no controle da praga é o uso de cultivares resistentes, contendo genes da bactéria Bacillus thuringiensis $(\mathrm{Bt})$, que começou a ser plantada no Brasil em 2013 [13], porém já existem relatos de infestação da praga nessas cultivares. Além disso, a soja Bt possui ação principalmente a lagartas em instares iniciais e cultivares de algodoeiro Bt apresentam, em geral, menor controle a $H$. armigera quando comparado à soja $\mathrm{Bt}[14,15]$.

A utilização de cultivares Bt apresenta como objetivo diminuir os custos com aplicações, facilitar o manejo, menor exposição aos produtos fitossanitários, proporcionar uma alta produtividade de forma sustentável, porém o não respeito ao plantio de áreas de refúgio tem favorecido que populações de insetos-praga desenvolvam resistência colocando a tecnologia em risco. Assim, temse por objetivo avaliar a atratividade, consumo foliar e preferência alimentar de $H$. armigera em cultivares de soja com diferentes tecnologias Bt.

\section{MATERIAL E MÉTODOS}

\subsection{Características gerais}

O experimento foi conduzido em área experimental, coordenadas geográficas $18^{\circ} 43^{\prime} 31,75^{\prime}$ ' $\mathrm{S}$, 47³1'32,06' 'W, altitude 890 metros, localizada no domínio dos Planaltos e Chapadas da Bacia Sedimentar do Paraná, no sudoeste do bioma Cerrado. De acordo com a classificação de Köppen, o clima da região é temperado úmido com inverno seco e verão quente (Cwa), com temperatura média anual de $22^{\circ} \mathrm{C}$ e precipitação média anual de $1.500 \mathrm{~mm}$, sendo as chuvas concentradas em seis meses, principalmente no período do verão. O tipo de solo predominante é LATOSSOLO VERMELHO argiloso. Para execução dos experimentos foram utilizadas seis cultivares de soja, 
sendo cinco contendo o gene Bt: SYN 15640 IPRO (cultivar 1, RNC 34132), SYN 1366C IPRO (cultivar 2, RNC 31461), Desafio 8473 RSF (cultivar 3, RNC 28779), L60162IPRO (cultivar 4, RNC 36892) e M7739IPRO (cultivar 5, RNC 29692); e uma sem o gene Bt, RK6813 RR (testemunha, RNC 30246). As sementes foram tratadas com fungicidas carbendazim + tiram (ingredientes ativos). As cultivares foram semeadas em vasos plásticos com capacidade de $11 \mathrm{~L}$, colocando-se 3 sementes/vaso, que foram mantidos em casa de vegetação, seguindo os tratos culturais determinados para a cultura da soja. No estádio V3, foi realizado o desbaste mantendo apenas uma planta, considerada a com melhor desenvolvimento, por vaso.

Em função da disponibilidade da soja no campo, foram executados dois experimentos, desenvolvidos durante os meses de novembro e dezembro de 2018 e janeiro e fevereiro de 2019 , utilizando as folhas da soja no estádio V5, que foram retiradas da planta e levadas ao laboratório para os testes de atratividade e preferência alimentar de $H$. armigera. As folhas foram recortadas em formato circular com diâmetros de 21,0 mm.

\subsection{Criação de Helicoverpa armigera}

As lagartas de Helicoverpa armigera foram obtidas do laboratório de criação da Empresa PROMIP, composta por populações coletadas em soja nos estados da BA, MT, SP e MG, criadas segundo a metodologia adaptada de Pinóia (2012) [16] com dieta artificial descrita por Vilela et al. (2014) [17]. As lagartas neonatas foram individualizadas e dispostas em potes plásticos e tubos de ensaio de vidro de fundo chato contendo dieta. A dieta foi trocada a cada dois dias até o estádio de pupa. A criação foi mantida em BOD na temperatura de $24 \pm 2^{\circ} \mathrm{C}$ e fotoperíodo de $12 \mathrm{~h}$.

As pupas foram transferidas para as gaiolas de PVC (25 pupas por tubo) e mantidas em câmara climatizada a $24 \pm 2{ }^{\circ} \mathrm{C}$ até a emergência dos adultos. Foi colocada dentro de cada tubo PVC uma solução de mel e água para alimentação dos adultos, que foi substituída a cada dois dias. Os adultos mortos foram periodicamente retirados dos tubos.

Os tubos de PVC foram revestidos por folhas de papel toalha para possibilitar a oviposição das mariposas e foram cobertas por tecido tipo tule. Cerca de 3-4 dias após a emergência dos adultos, as fêmeas iniciaram a postura, principalmente na parte superior do tubo, onde foi colocado o tecido. De acordo com a quantidade de ovos, as folhas de papel e o tule com os ovos foram recolhidos e substituídos por novos. O papel e tecido com os ovos foram dispostos em vasilhas plásticas para eclosão das lagartas.

\subsection{Testes de atratividade e preferência alimentar}

Para a avalição de atratividade, foi liberada uma lagarta de $H$. armigera em terceiro instar no centro da placa de Petri $(15 \mathrm{~cm}$ de diâmetro x 2,5 cm de altura) contendo quatro discos foliares (com área média de 176,62 $\mathrm{cm}^{2}$ ), sendo dois discos de uma das cultivares de soja Bt e dois discos da cultivar não-Bt. Foi adicionado ágar para evitar a perda da turgência das folhas. As placas permaneceram fechadas durante o tempo de execução do experimento.

Foram realizadas cinco repetições por tratamento. Antes da instalação dos ensaios as lagartas de terceiro instar foram submetidas às $48 \mathrm{~h}$ de jejum. Foram avaliadas as lagartas presentes nos discos foliares durante cinco dias, a cada duas horas, iniciando às $10 \mathrm{~h}$ e finalizando às $18 \mathrm{~h}$. Com o auxílio de uma câmera de celular foram registrados os momentos de cada avaliação e com programa Image $\mathrm{J}^{\circledR}$, foi mensurada a área foliar dos discos consumida pelas lagartas em cada uma das avaliações.

$\mathrm{Na}$ avaliação da preferência alimentar pelas cultivares de soja, uma lagarta foi disposta na área central da placa de Petri $(50 \mathrm{~cm}$ de diâmetro x $10 \mathrm{~cm}$ de altura) juntamente com dois discos de cada cultivar, dispostos de forma equidistante, resultando em doze discos foliares por placa. Durante cinco dias foi avaliada a presença das lagartas presentes nos discos após a liberação. Ambos os experimentos foram mantidos em B.O.D. a $24 \pm 2^{\circ} \mathrm{C}$ e fotoperíodo de $12 \mathrm{~h}$ e realizados de acordo com metodologia adaptada de Santos et al. (2017) [18].

Para o primeiro teste, onde cada cultivar transgênica foi colocada junto com a testemunha (cultivar RK6813 RR), os possíveis comportamentos de alimentação da lagarta foram avaliados: 1) 
alimentação da cultivar transgênica; 2) alimentação da testemunha; 3 ) alimentação da cultivar transgênica e testemunha; 4) sem alimentação. Para cada horário analisado foi avaliada a preferência alimentar e consumo foliar de cinquenta lagartas.

No segundo teste, as cinco cultivares e a testemunha (cultivar RK6813 RR) foram oferecidas para as lagartas, e os seguintes comportamentos de alimentação foram observados: 1) alimentação de uma cultivar transgênica; 2) alimentação de duas cultivares transgênicas; 3) alimentação de três cultivares transgênicas; 4) alimentação de quatro cultivares transgênicas; 5) alimentação de cinco cultivares transgênicas; 6) alimentação da testemunha; 7) alimentação da testemunha e transgênico; 8) alimentação de todas cultivares; 9) sem alimentação. A avaliação realizada foi independente das cultivares transgênicas utilizadas, objetivando-se observar o padrão de preferência da lagarta entre cultivares transgênicas versus não transgênica. Para cada horário analisado foi avaliada a preferência alimentar e o consumo foliar de cinquentas lagartas.

\subsection{Análise de resultados}

Os padrões observados em cada horário foram submetidos ao teste de Qui Quadrado $\left(\mathrm{X}^{2}\right)$, comparando-os com o padrão aleatório, com o objetivo de se avaliar se há preferência da lagarta em alimentar-se da cultivar transgênica ou se o comportamento de alimentação da lagarta é aleatório e independe do evento Bt da cultivar. Com relação ao consumo foliar, os dados foram submetidos ao teste de $t$ de Student. Os testes foram executados pelo software R versão 3.5.0.

\section{RESULTADOS}

\subsection{Teste de atratividade}

Em relação à atratividade de lagartas às cultivares de soja verificou-se que houve presença de lagartas de $H$. armigera nas cultivares $\mathrm{Bt}$ e na testemunha variando ao longo das avaliações (tempo), ou seja, as lagartas visitaram todos os discos presentes na placa (Figuras 1 e 2). Para todos os dias de avaliação, quando houve baixa ou nenhuma presença de lagartas nos discos foliares nos tempos de avaliação foi feita a média da frequência.

No primeiro dia de avaliação obteve-se que não houve presença de lagartas em nenhum disco foliar nos tratamentos com as cultivares 1 e 5 , porém houve presença na testemunha nos tratamentos com as cultivares 2, 3 e 4 e apenas no tratamento com a cultivar 4 houve presença no disco foliar da cultivar transgênica (Figura 1A).

No segundo dia de avaliação na cultivar 2, somente os discos da testemunha foram encontradas lagartas, porém no tratamento com a cultivar 3 as lagartas também estavam presentes nos discos da cultivar Bt, além da testemunha. Na cultivar 4 a partir da quarta avaliação verificou-se presença na cultivar Bt. Somente no tratamento com a cultivar 5 não houve presença em nenhum dos discos (Figura 1B). No terceiro dia de avaliação, houve presença em todos os discos do tratamento cultivar 3 (disco foliar Bt e testemunha) e na cultivar 2 a presença ocorreu apenas da testemunha. Verificouse também o primeiro registro de ocorrência de lagartas na cultivar 5 (Figura 1C), o que ocorreu apenas nesse dia durante toda a avaliação.

No quarto dia de avaliação, no tratamento cultivar 5 houve presença apenas nos discos da cultivar testemunha, enquanto outras não se direcionaram aos discos foliares. Na cultivar 2, as lagartas estavam presentes em todos os discos da testemunha. Na cultivar 3 foi observada a presença na cultivar transgênica e na testemunha (Figura 1D). No último dia de avaliação houve presença nas cultivares Bt 1 e 4, enquanto na cultivar 3 as lagartas estavam em ambos os discos (testemunha e Bt), nos demais tratamentos, 2 e 5 , não houve lagartas presentes ou estas se alimentaram apenas da testemunha (Figura 1E). Lagartas mortas não foram substituídas por outras e a avaliação no tratamento foi finalizada. 

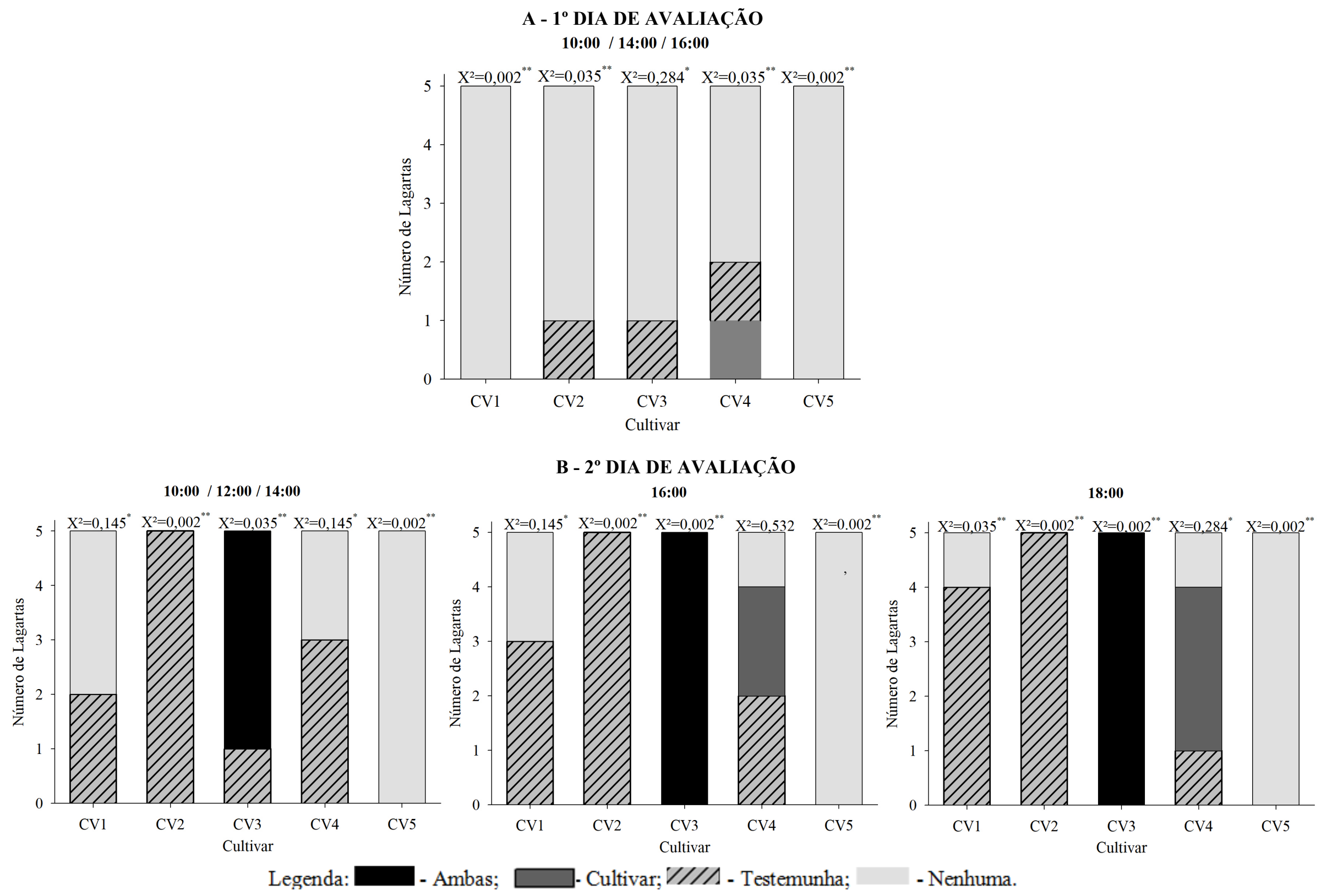

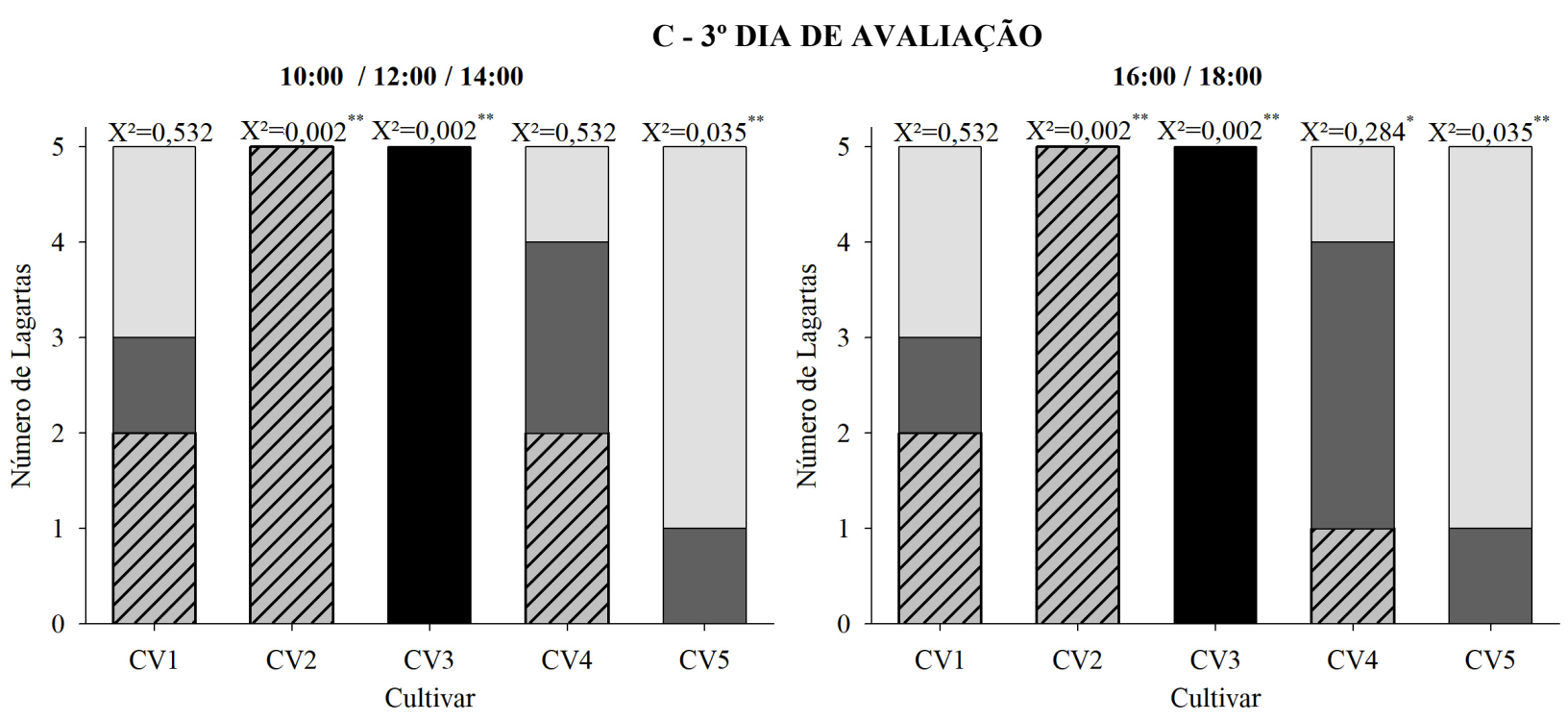

10:00 / 12:00 / 14:00

D - 4º DIA DE AVALIAÇÃO
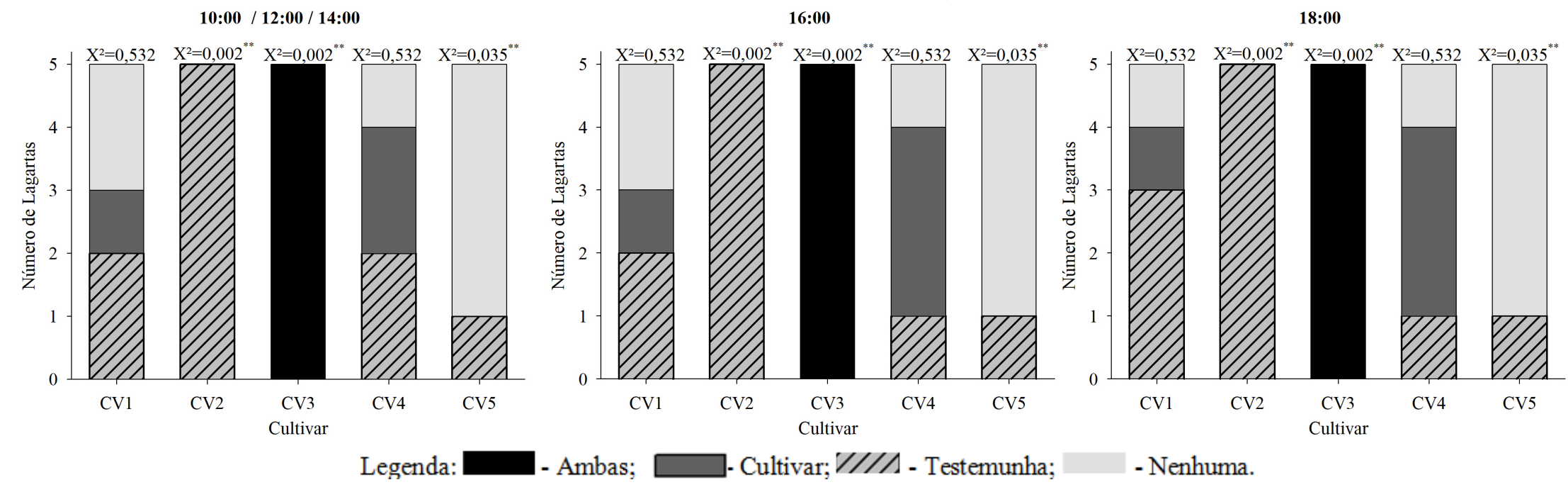

- Nenhuma. 
E - 5 DIA DE AVALIAÇ̃̃o

$10: 00 / 12 \cdot 00 / 14: 00$

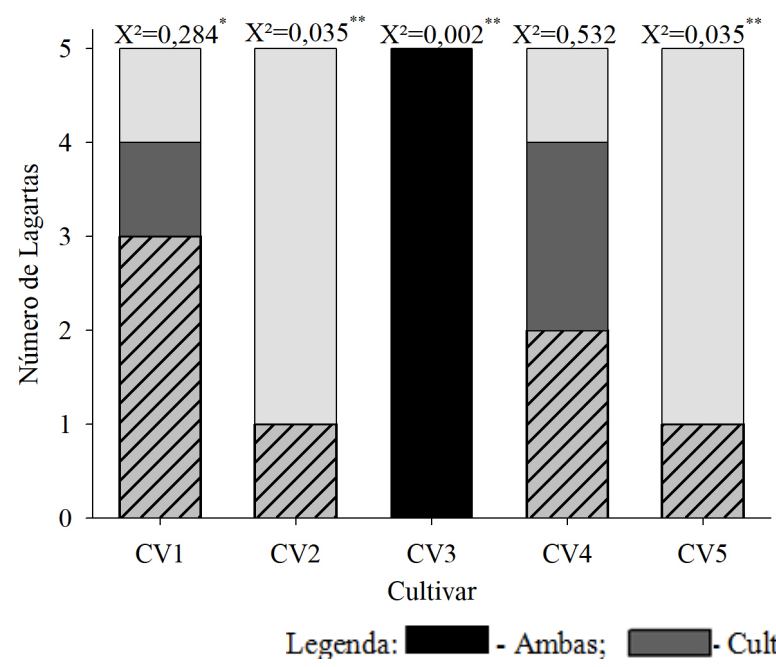

$16: 00 / 18: 00$

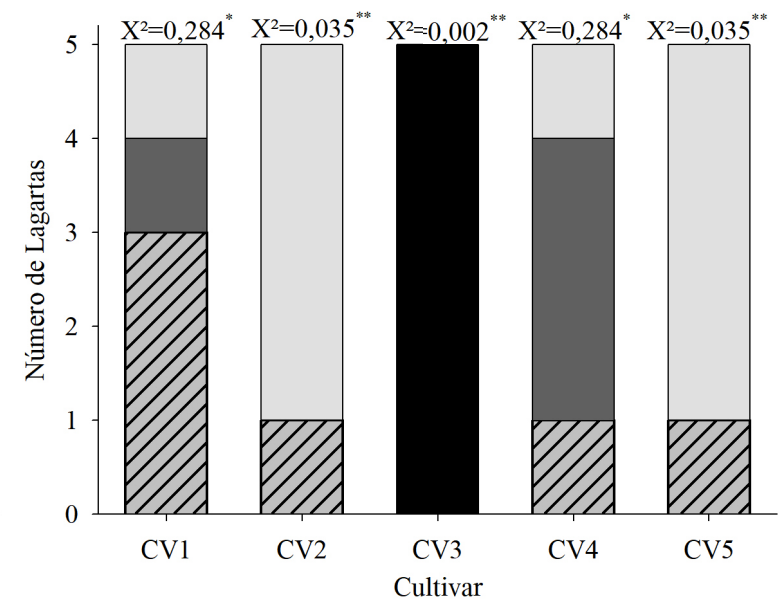

Figura 1: Frequência média de lagartas de Helicoverpa armigera em folhas de diferentes cultivares de soja em teste de atratividade. A. Primeiro dia de avaliação. B. Segundo dia de avaliação. C. Terceiro dia de avaliação. D. Quarto dia de avaliação. E. Quinto dia de avaliação ${ }^{*}$ Significativo a 0,05 de significância. ${ }^{* *}$ Significativo a 0,01 de significância. 
Com relação ao consumo de área foliar no teste de atratividade, apenas as cultivares 1 e 2 foram menos consumidas que as testemunhas. Não houve diferença no consumo da cultivar 3 em relação à testemunha. Para a cultivar 4 apesar do baixo consumo da cultivar $\mathrm{Bt}$, este não diferiu da testemunha em função da elevada variação que ocorreu entre as repetições desse tratamento (Tabela 1). Na cultivar 5 , apesar de ter sido registrada a presença de lagartas nos discos foliares (Figura 2B) não houve consumo (Tabela 1).

Tabela 1: Porcentagem de área consumida por lagartas de Helicoverpa armigera em folhas de diferentes cultivares de soja após cinco dias de avaliação, em teste de atratividade.

\begin{tabular}{lc}
\hline Tratamento & Área foliar consumida (\%) $^{*}$ \\
\hline Cultivar 1 & $25,13 \pm 13,47 \mathrm{~b}$ \\
Testemunha & $53,02 \pm 15,19 \mathrm{a}$ \\
\hline Cultivar 2 & $13,66 \pm 7,30 \mathrm{~b}$ \\
Testemunha & $98,75 \pm 1,26 \mathrm{a}$ \\
\hline Cultivar 3 & $86,37 \pm 7,20 \mathrm{a}$ \\
Testemunha & $78,75 \pm 10,88 \mathrm{a}$ \\
\hline Cultivar 4 & $25,60 \pm 30,62 \mathrm{a}$ \\
Testemunha & $60,27 \pm 34,52 \mathrm{a}$ \\
\hline Cultivar 5 & $0,00 \pm 0,00 \mathrm{a}$ \\
Testemunha & $3,09 \pm 3,09 \mathrm{a}$ \\
\hline
\end{tabular}

*Médias seguidas com letras iguais não se diferenciaram pelo teste de $t$ de Student a 0,05 de significância na comparação entre cultivar e testemunha.

\subsection{Teste de preferência alimentar}

Para o experimento de preferência, no primeiro dia de avaliação foi observado que a maioria das lagartas não se direcionou para nenhuma cultivar (Figura 2A), dentre as cultivares que tiveram maior direcionamento de lagartas o tratamento com a testemunha foi a que apresentou maior quantidade. No segundo dia, no primeiro horário de avaliação, foi observada presença de lagartas na testemunha e em três cultivares Bt. Não foi verificada a presença de lagartas nos discos foliares das cultivares 4 e 5 no segundo dia de avaliação (Figura 2B). No terceiro dia de avaliação foi verificada presença de lagartas na cultivar 4 a partir do segundo horário de avaliação e presença de lagarta na cultivar 5 apenas na última avaliação do dia. Assim, na última avaliação verificou-se a presença de lagartas em todas as cultivares (Figura 2C).

Foi feita a média da presença de lagartas nos dois últimos dias de avaliação (quarto e quinto dias), verificando-se que a maioria das lagartas estava presente em pelo menos uma cultivar transgênica e a testemunha, além de não ocorrer presença na cultivar 1 (Figura 2D). Vale ressaltar que após esse período algumas lagartas cessaram o consumo e entraram nas fases de pré-pupa e pupa. 
A - $1^{\circ}$ DIA DE AVALIAÇÃO

14:00 / 16:00 / 18:00

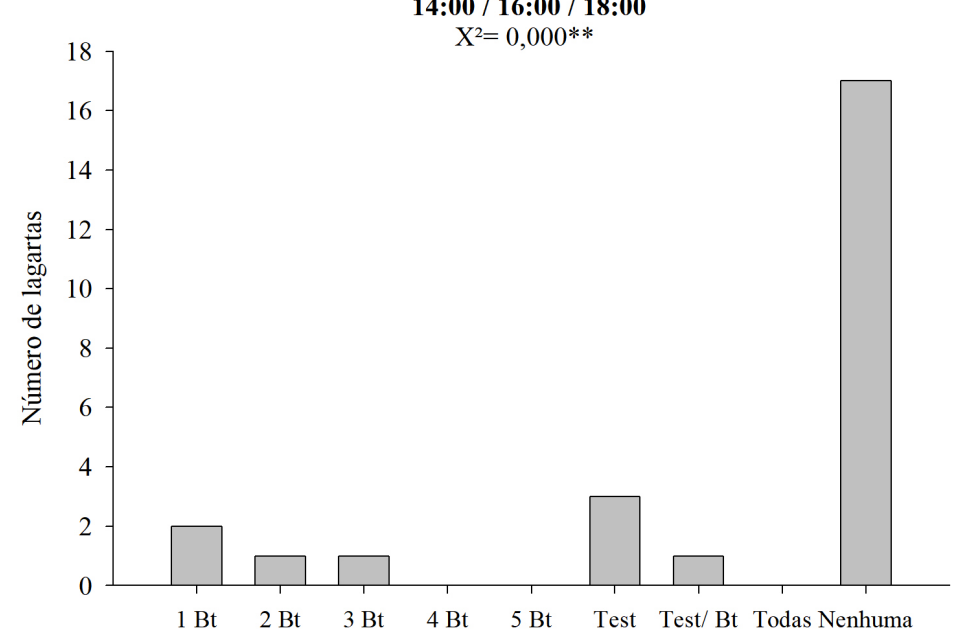

B - 2 DIA DE AVALIAÇÃO
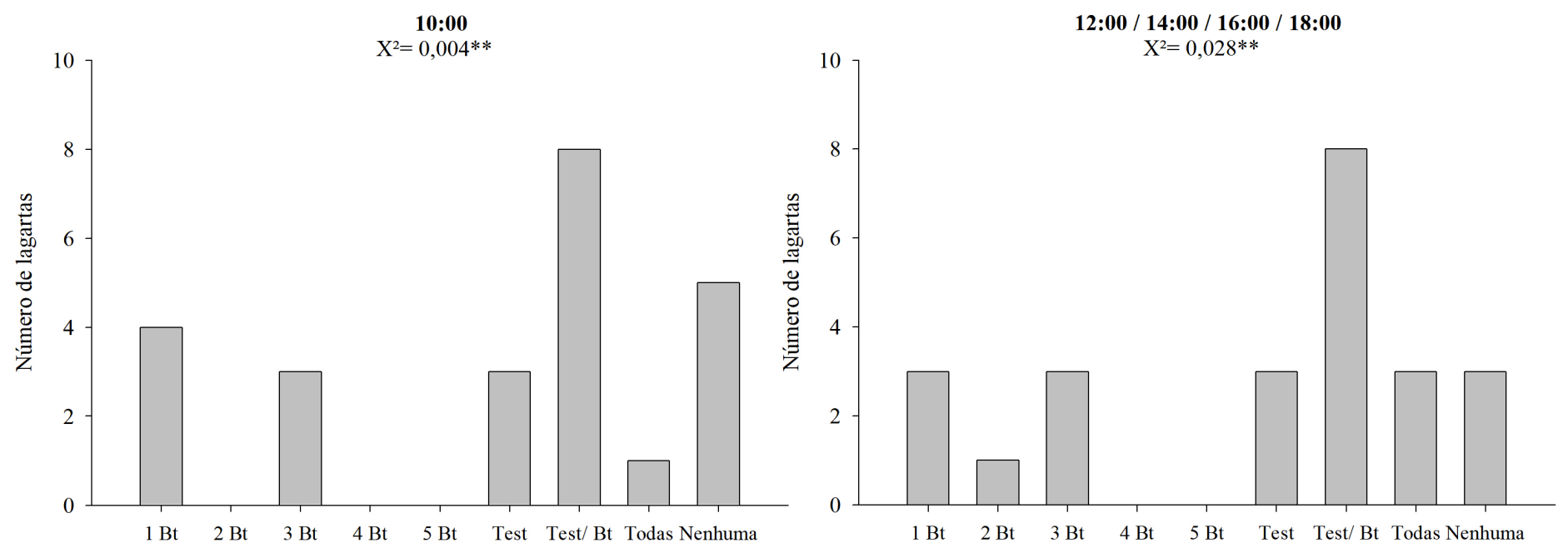


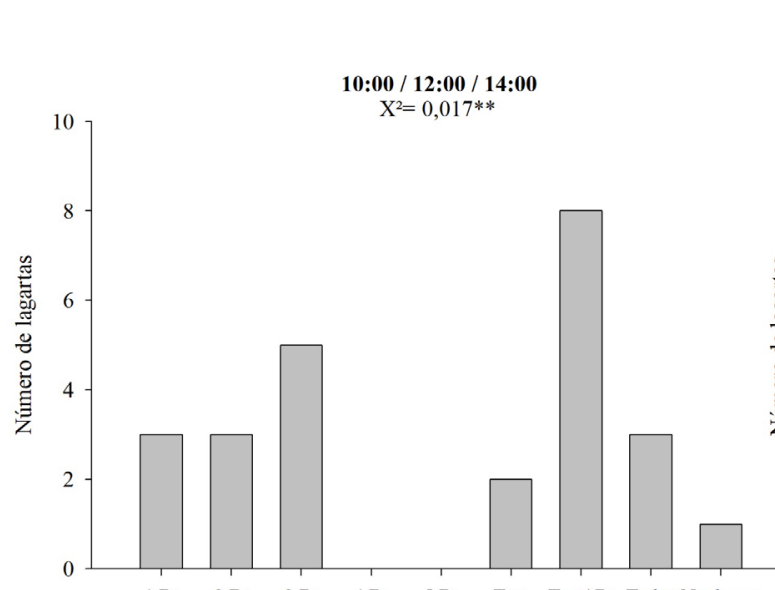

$1 \mathrm{Bt} \quad 2 \mathrm{Bt} \quad 3 \mathrm{Bt} \quad 4 \mathrm{Bt} \quad 5 \mathrm{Bt} \quad$ Test $\quad$ Test/ Bt Todas Nenhuma
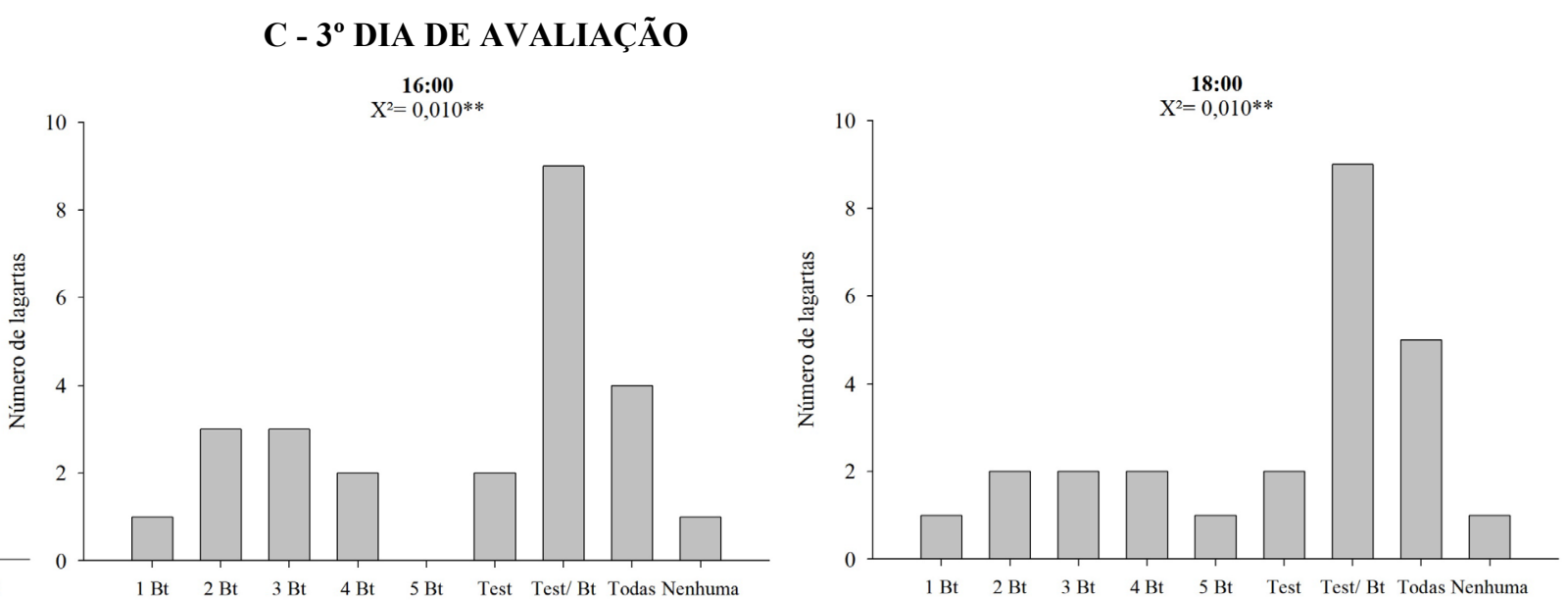

\section{D - $4^{\circ}$ E $5^{\circ}$ DIAS DE AVALIAÇÃO}

10:00 / 12:00 / 14:00 / 16:00 / 18:00

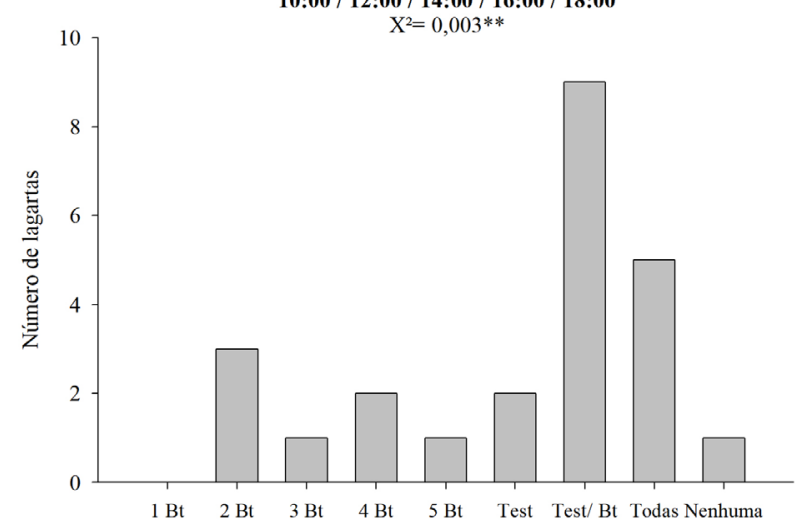

Figura 2: Frequência de lagartas de Helicoverpa armigera em folhas de diferentes cultivares de soja em diferentes intervalos de tempo em teste de preferência alimentar. A. Primeiro dia de avaliação. B. Segundo dia de avaliação. C. Terceiro dia de avaliação. D. Quarto e quinto dias de avaliação. ${ }^{* *}$ Significativo a 0,01 de significância. 


\section{DISCUSSÃO}

Santos et al. (2017) [18] também observaram que lagartas de H. armigera não apresentaram preferência alimentar por folhas de cultivares de soja com e sem tecnologia Bt. Além disso, os autores verificaram que as fêmeas não diferenciaram as cultivares para oviposição, indicando que a presença de cultivares Bt não alterou o comportamento do inseto. Zalucki et al. (2012) [19] observaram que mariposas de Helicoverpa spp. não evitaram ovipositar em plantas de algodoeiro transgênico, destacando a necessidade de manutenção de plantio de áreas de refúgio para diminuir a evolução de resistência. Assim, as diferenças observadas de preferência ou repelência para alimentação entre os tratamentos, mesmo entre as cultivares $\mathrm{Bt}$, podem estar relacionadas a outros fatores, como características físicas. Coelho et al. (2020) [20], por exemplo, avaliaram a expressão da resistência de plantas de soja sem tecnologia Bt a $H$. armigera e obtiveram genótipos que reduziram o consumo foliar e reduziram o peso de lagartas de quinto instar, demonstrando que ocorreu não preferência ou antixenose pelos genótipos testados.

Zhao et al. (2016) [21] verificaram que populações de $H$. armigera evitaram ovipositar e se alimentar de plantas de algodoeiro Bt, verificando que ocorreu preferência por plantas não $\mathrm{Bt}$, o que segundo Kumar e Saini (2008) [22] pode ocorrer em função de plantas com elevada presença de compostos como fenóis, taninos, gossipol e potássio serem negativamente relacionadas com a ocorrência de infestações de $H$. armigera, enquanto a presença de açúcares, proteínas e nitrogênio correlacionem positivamente à ocorrência de infestações da praga em cultivares de algodoeiro.

Luong et al. (2016) [23] observaram que não houve diferença na atratividade e preferência alimentar de $H$. armigera a cultivares $\mathrm{Bt}$ e não-Bt, demonstrando que a presença da toxina Cry1 Ac não teve efeito repelente às lagartas. Os autores destacaram que apesar de não ocorrer preferência, após seis dias houve maior mortalidade de lagartas que se alimentaram em plantas Bt. Resultados semelhantes foram observados por Wei et al. (2015) [24] verificando que não houve diferença no comportamento alimentar de $H$. armigera em relação ao consume de folhas de algodoeiro Bt e nãoBt em ensaios realizados com e sem chance de escolha. No entanto, Rao e Rao (2008) [25] obtiveram resultados distintos, sendo que lagartas de terceiro instar iniciaram a alimentação em plantas Bt, porém logo após a primeira prova cessaram a alimentação. Assim, as variações observadas no consumo das cultivares por $H$. armigera do presente estudo podem estar relacionadas a fatores como qualidade nutricional de cada cultivar.

Estudos mostram que a soja sob o ataque de insetos-praga, produz flavonoides, principal metabólito secundário que atua na defesa da planta, prejudicando o desempenho biológico do inseto. No entanto, a presença e a concentração de alomônios são variáveis em diferentes cultivares, além disso, os insetos pragas podem modificar sua estrutura, ficando invulneráveis a essas substâncias e até mesmo as proteínas produzidas pelo gene Bt. Esse processo é percebido em $H$. armigera que produz proteínas capazes de desintoxicação quando se alimenta com o gossipol, por exemplo [26, 27].

$\mathrm{O}$ comportamento dos insetos em relação às cultivares $\mathrm{Bt}$ pode mudar ao longo do tempo em função da coevolução existente entre as espécies, sendo que o inseto poderá começar a reconhecer e evitar o hospedeiro $\mathrm{Bt}$ e ter preferência por plantas não-Bt [23, 28]. Estudo realizado com populações de $H$. armigera no Brasil não verificou ocorrência de resistência à soja $\mathrm{Bt}$, demonstrando alta suscetibilidade desse inseto à soja transgênica, porém os autores destacam a importância da utilização de áreas de refúgio a fim de atrasar o processo de evolução de resistência de H. armigera a soja Bt [29]. No entanto, de acordo com Pinto et al. (2017) [30] em função dos registros em diversos países de resistência de $H$. armigera a diferentes tecnologias Bt, pode-se inferir que população introduzidas no Brasil já possam conferir características de resistência.

Diferentes estudos em países onde $H$. armigera está presente há maior tempo em contato com plantas Bt têm demonstrado a ocorrência de casos de resistência a essas cultivares, como demonstrado por Zhang et al. (2011) [31] e Alvi et al. (2012) [32] em algodoeiro Bt, que sugerem que a rotação com plantas não-Bt podem auxiliar a reduzir a pressão de seleção de plantas Bt a $H$. armigera. Trabalhos futuros devem ser desenvolvidos a fim de verificar a mortalidade de lagartas e o desenvolvimento de $H$. armigera até a fase adulta, o que leva a possibilidade de verificar o efeito de cultivares Bt sobre o inseto. Assim, testes que se referem à $H$. armigera e cultivares de 
soja Bt são importantes para o acompanhamento de resistência nas populações do inseto presentes no Brasil.

\section{CONCLUSÃO}

Foi observado que as lagartas de H. armigera consumiram todas as cultivares de soja testadas, demonstrando que não houve diferenciação entre a cultivar não Bt e as cultivares Bt.

A cultivar Desafio 8473 RSF (cultivar 3) e L60162IPRO (cultivar 4) foram consideradas atrativas para $H$. armigera, enquanto a cultivar M7739IPRO (cultivar 5) foi considerada pouco atrativa.

$\mathrm{Na}$ avaliação de consumo foliar, as cultivares Desafio 8473 RSF (cultivar 3) e L60162IPRO (cultivar 4) foram consideradas atrativas para o consumo.

Em relação ao teste de preferência alimentar, verificou-se que a cultivar M7739IPRO (cultivar 5) foi a que teve menor preferência para alimentação de lagartas de H. armigera.

\section{AGRADECIMENTOS}

Os autores agradecem à Pró-reitora de Pesquisa e Pós-graduação da Universidade Federal de Uberlândia e ao CNPq pela concessão de bolsa de iniciação científica para a primeira autora e pelo suporte para o desenvolvimento da pesquisa.

\section{REFERÊNCIAS BIBLIOGRÁFICAS}

1. Conab - Companhia Nacional de Abastecimento. Acompanhamento da safra brasileira de grãos, v. 7 Safra 2019/2020 - Oitavo levantamento [Internet]. Brasília: Conab, 2020. 66 p. Disponível em: https://www.conab.gov.br/info-agro/safras/graos/boletim-da-safra-de-graos [Acesso em 9 Nov 2020].

2. Secex. Secretaria de Comércio Exterior. Ministério da Indústria, Comércio Exterior e Serviços. Comex Stat. Disponível em: http://comexstat.mdic.gov.br/pt/comex-vis (Termos pesquisados: Visualição $=$ Produtos; Detalhamento $=$ Soja).

3. Ávila CJ, Vivan LM, Tomquelski GV. Ocorrência, aspectos biológicos, danos e estratégias de manejo de Helicoverpa armigera (Hübner) (Lepidoptera: Noctuidae) nos sistemas de produção agrícolas. Dourados: Embrapa, Circular técnica; 2013. 12 p.

4. Czepak C, Albernaz KC, Vivan LM, Guimarães HO, Carvalhais T. Primeiro registro de ocorrência de Helicoverpa armigera (Hübner) (Lepidoptera: Noctuidae) no Brasil. Pesq Agropec Trop. 2013;43(1):110113, doi: 10.1590/S1983-40632013000100015

5. Sosa-Gómez DR, Specht A, Paula-Moraes SV, Lopes-Lima A, Yano SAC, Micheli A, Morais EGF, Gallo P, Pereira PRVS, Salvadori JR, Botton M, Zenker MM, Azevedo-Filho WS. Timeline and geographical distribution of Helicoverpa armigera (Hübner) (Lepidoptera, Noctuidae: Heliothinae) in Brazil. Rev Bras Entomol. 2016;60:101-104, doi: 10.1016/j.rbe.2015.09.008

6. Suzana CS, Rosa CF, Alves F da L, Salvadori JR. Consumption and use of soybean by the caterpillar Helicoverpa armigera. Ciênc Rural. 2018;48(12):e20180188, doi: 10.1590/0103-8478cr20180188

7. Bortolotto OC, Bueno AF, Braga K, Barbosa GC, Sanzovo A. Biological characteristics of Heliothis virescens fed with Bt -soybean MON $87701 \times$ MON 89788 and its conventional isoline. An Acad Bras Ciênc. 2014;86(2):973-980, doi: 10.1590/0001-3765201420130495

8. Rogers DJ, Brier HB. Pest-damage relationships for Helicoverpa armigera (Hubner) (Lepidoptera: Noctuidae) on soybean (Glycine max) and dry bean (Phaseolus vulgaris) during pod-fill. Crop Prot. 2010;29:47-57, doi: 10.1016/j.cropro.2009.08.015

9. Czepak C, Tay WT, Guimaraes HO, Carvalhais T, Senechal ML, Silvério RF. Duas em uma. Cultivar Grandes Culturas. 2018 Jun;229:30-33.

10. Mapa. Ministério da Agricultura, Pecuária e Abastecimento. Agrofit, 2020. [Internet]. Disponível em: http://agrofit.agricultura.gov.br/agrofit_cons/principal_agrofit_cons [Acesso em 9 Nov 2020]

11. Kuss CC, Roggi RCRK, Basso CJ, Oliveira MCN de, Pias OH de C, Roggia S. Controle de Helicoverpa armigera (Lepidoptera: Noctuidae) em soja com inseticidas químicos e biológicos. Pesq Agropec Bras. 2016;51(5):527-536, doi: 10.1590/S0100-204X2016000500013

12. Pereira RM, Neto DA, Amado D, Durigan MR, Franciscatti RA, Mocheti M, Omoto C. Baseline susceptibility and frequency of resistance to diamide insecticides in Helicoverpa armigera (Lepidoptera: Noctuidae) populations in Brazil. Crop Prot. 2020;137:1-31, doi: 10.1016/j.cropro.2020.105266 
13. Yano SAC, Specht A, Moscardi F, Carvalho RA, Dourado PM, Martinelli S, Head GP, Sosa-Gómez DR. High susceptibility and low resistance allele frequency of Chrysodeixis includens (Lepidoptera: Noctuidae) field populations to CrylAc in Brazil. Pest Manag. Sci. 2016;72:1578-1584, doi: $10.1002 /$ ps.4191

14. Pomari-Fernandes A; Bueno A de F, Sosa-Gómez D R. Helicoverpa armigera: current status and future perspectives in Brazil. Curr Agric Sci Technol. 2015;21:1-7, doi: 10.18539/cast.v21i1.4234

15. Teese MG, Farmswoeth CA, Li Y, Coppin CW, Devonshire AL, Scott C, East P, Russell RJ, Oakeshott JG. Heterologous expression and biochemical characterisation of fourteen esterases from Helicoverpa armigera. PLoS One. 2013;8(6):e65951, doi: 10.1371/journal.pone.0065951

16. Pinóia SSF. Eficácia de Bacillus thuringiensis (Berliner) e spinosade no combate a Helicoverpa armigera (Hbn) (Lepidoptera: Noctuidae) em tomateiro [dissertação]. Lisboa: Universidade Técnica de Lisboa; 2012. 65 p.

17. Vilela M, Mendes SM, Valicente FH, Carvalho SSS, Santos AE, Santos CA, Barbosa TAN, Carvalho EAR, Costa VHD. Metodologia para criação e manutenção de Helicoverpa armigera em laboratório. Sete Lagoas: Embrapa, Circular técnica 203; 2014. 7 p.

18. Santos VB, Silva LB, Carneiro E, Silva AF, Lopes GN, Pavan BE, Rodrigues TF. Comparative study of Helicoverpa armigera (Hubner) (Lepidoptera: Noctuidae) preference for Bt and non-Bt soybean cultivars. Am J Plant Sci. 2017;8:2483-2500, doi: 10.4236/ajps.2017.810169

19. Zalucki MP, Cunningham JP, Downes S, Ward P, Lange C, Meissle M, Schellhorn NA, Zalucki JM. No evidence for change in oviposition behaviour of Helicoverpa armigera (Hübner) (Lepidoptera: Noctuidae) after widespread adoption of transgenic insecticidal cotton. B Entomol Res. 2012;102:468476, doi:10.1017/S0007485311000848

20. Coelho M, Godoy AF, Baptista YA, Bentivenha JPF, Lourenção AL, Baldin ELL, Catchot AL. Assessing soybean genotypes for resistance to Helicoverpa armigera (Lepidoptera: Noctuidae). J Econ Entomol. 2020;113(1):471-481, doi: 10.1093/jee/toz269

21. Zhao D, Zalucki MP, Guo R, Fang Z, Shen W, Zhang L, Liu B. Oviposition and feeding avoidance in Helicoverpa armigera (Hübner) against transgenic Bt cotton. J Appl Entomol. 2016;140:715-724, doi: 10.1111/jen.12304

22. Kumar S, Saini RK Feeding preference and damage potential of Helicoverpa armigera (Hübner) on different promising cotton genotypes/hybrid. J Agri Sci Tech. 2008;10:411-420.

23. Luong TT, Downes SJ, Cribb B, Perkins LE, Zalucki MP. Oviposition site selection and survival of susceptible and resistant larvae of Helicoverpa armigera (Lepidoptera: Noctuidae) on $\mathrm{Bt}$ and non-Bt cotton. Bull Entomol Res. 2016;106:710-717, doi: 10.1017/S0007485316000328

24. Wei J, Guo Y, Liang G, Wu K, Zhang J, Tabashnik BE, Li X. Cross-resistance and interactions between Bt toxins Cry1 Ac and Cry2Ab against the cotton bollworm. Sci Rep. 2015;5:1-7, doi: 10.1038/srep07714

25. Rao NS, Rao PA Behavioural and physiological effects of Bt cotton on cotton bollworm, Helicoverpa armigera (Hub). J Entomol Res. 2008;32:273-278.

26. Celorio-Mancera P de la M, Ahn SJ, Vogel H, Heckel DG. Transcriptional responses underlying the hormetic and detrimental effects of the plant secondary metabolite gossypol on the generalist herbivore Helicoverpa armigera. BMC Genomics. 2011;12(575):1471-2164, doi: 10.1186/1471-2164-12-575

27. Piubelli GC, Hoffmann-Campo CB, Moscardi F, Miyakubo S, Oliveira MCN de. Are chemical compounds important for soybean resistance to A. gemmatalis? J Chem Ecol. 2005;31(7):1509-1524, doi: 10.1007/s10886-005-5794-Z

28. Jongsma MA, Gould F, Legros M, Yang L, Van Loon JJA, Dicke M. Insect oviposition behavior affects the evolution of adaptation to Bt crops: consequences for refuge policies. Evol Ecol. 2010;24:1017-1030, doi: 10.1080/02571862.2006.10634744

29. Dourado PM, Bacalhau FB, Amado D, Carvalho RA, Martinelli S, Head GP, Omoto C. High susceptibility to Cry1Ac and low resistance allele frequency reduce the risk of resistance of Helicoverpa armigera to Bt soybean in Brazil. Plos One. 2016;11(8):e0161388, doi: 10.1371/journal.pone.0161388

30. Pinto FA, Mattos MVV, Silva FWS, Rocha SL, Elliot SL. The spread of Helicoverpa armigera (Lepidoptera: Noctuidae) and coexistence with Helicoverpa zea in Southeastern Brazil. Insects 2017;8(87):1-5, doi:10.3390/insects8030087

31. Zhang H, Yin W, Zhao J, Jin L, Yang Y, Wu S, Tabashnik BE, Wu Y. Early warning of cotton bollworm resistance associated with intensive planting of Bt cotton in China. Plos One. 2011;6(8):e22874, doi: 10.1371/journal.pone.0022874

32. Alvi AHK, Sayyed AH, Naeem M, Ali M. Field evolved resistance in Helicoverpa armigera (Lepidoptera: Noctuidae) to Bacillus thuringiensis toxin Cry1Ac in Pakistan. Plos One. 2012; 7(10):e47309, doi: 10.1371/journal.pone.0047309 